\title{
The Effect of Taurine on the Cholesterol Metabolism in Rats Fed Diets Supplemented with Cholestyramine or High Amounts of Bile Acid
}

\author{
Naomichi NishImURA*, Chie UMEDA, Hiroaki ODA ${ }^{1}$ and Hidehiko YoKOGosHI \\ School of Food and Nutritional Sciences, The University of Shizuoka, 52-1 Yada, Shizuoka 422-8526, Japan \\ ${ }^{1}$ Department of Applied Biological Sciences, Nagoya University, Nagoya 464-8601, Japan
}

(Received May 20, 2002)

\begin{abstract}
Summary The effects of taurine on serum cholesterol levels and hepatic cholesterol $7 \alpha$ hydroxylase activity (CYP7A1) were studied in rats fed cholestyramine or high amounts of sodium cholate in order to alter the intestinal pool of bile acids. Rats were fed a diet supplemented with $1 \%$ cholesterol and $0.25 \%$ sodium cholate (high cholesterol, control; $\mathrm{C}$ ), and C supplemented with $4 \%$ cholestyramine $(\mathrm{CH})$ or $0.75 \%$ sodium cholate $(\mathrm{BA})$ for $14 \mathrm{~d}$. Taurine groups were fed the diet supplemented with $3 \%$ taurine (CT, CHT and BAT). Compared to rats fed $\mathrm{C}$ and $\mathrm{BA}$ diets, serum cholesterol levels were significantly reduced in rats fed CT and BAT diets, but a significant reduction of serum cholesterol by taurine feeding was not observed in the CHT group as compared to the $\mathrm{CH}$ group. An increase in hepatic CYP7A1 activity due to taurine intake was observed in the CT and BAT groups. However, the simultaneous administration of cholestyramine and taurine (CHT group) did not increase hepatic CYP7A1 activity compared the intake of cholestyramine only (CH group). A significant increase in fecal bile acid excretion due to taurine intake was found only in rats fed the CT diet. In conclusion, it is suggested that taurine facilitates hepatic CYP7A1 activity regardless of the enlarged intestinal pool of bile acids due to increased intake of exogenous bile acid, and then reduces the serum cholesterol concentration.
\end{abstract}

Key words taurine, cholesterol, bile acid, cholesterol $7 \alpha$-hydroxylase, rats

Cholesterol is an essential component for biological membranes and is a precursor of a steroid hormone. Thus, cholesterol metabolism is strictly regulated by enzyme reactions and gene expression, resulting in normal cholesterol homeostasis. The disturbance of the cholesterol homeostatic mechanism due to high cholesterol intake ultimately provokes elevation of the serum cholesterol levels, thus being involved in the development of coronary heart diseases (1) and atherosclerosis (2). It is therefore very important to lower the serum cholesterol concentration to prevent these diseases.

Tsuji et al. (3) found that serum and liver cholesterol concentrations were lowered by the intake of taurine in rats fed cholesterol-enriched diets. Many works have been devoted to studying the effect of dietary taurine on serum cholesterol concentration in animals fed a high cholesterol diet, and the hypocholesterolemic effect of taurine feeding has been identified (4-6). We have also observed the hypocholesterolemic effect of taurine in hypercholesterolemic rats induced by dietary cholesterol (7) and other factors such as diabetes mellitus, hypothyroid, and xenobiotics $(8-10)$. In addition, taurine feeding increases the fecal excretion of bile acids accompanied by the induction of cholesterol $7 \alpha$-hydroxylase

* To whom correspondence should be addressed at present address: Nayoro City College, Department of Human Life and Development, Kita-8-1, Nishi-2, Nayoro, Hokkaido 096-8641, Japan

E-mail: nishimura@nayoro.ac.jp
(CYP7A1) activity and its gene expression (7). On the other hand, taurine itself did not induce hepatic CYP7A1 gene expression when incubated in primary rat-cultured hepatocytes (our unpublished data). Thus, the induction of CYP7A1 by dietary taurine is a secondary effect to the gene expression of CYP7A1.

The induction of hepatic CYP7A1 by taurine intake may be mediated through the increased secretion of bile acid because taurine plays a role in the conjugation of bile acid. Increased bile acid secretion results in expansion of the intestinal pool of bile acid and increased activity of hepatic CYP7A1 (11). Hepatic CYP7A1 is also affected by the variation of bile acid pool size in the intestine (12). There have been no studies to examine the hypocholesterolemic effect of taurine in rats whose intestinal pool of bile acid was altered. In the present study, we examined the effect of taurine on serum cholesterol concentration and hepatic CYP7A1 activity when rats were fed cholestyramine and a high amount of sodium cholate. Cholestyramine feeding increases the intestinal pool and fecal excretion of bile acids due to the inhibition of bile acid absorption from the ileum, whereas high bile acid feeding elevated them owing to the overflow of unabsorbed dietary bile acid. Pandak et al. reported that hepatic CYP7A1 activity rose $200 \%$ in rats fed a $5 \%$ cholestyramine diet, while a $1 \%$ sodium cholate diet decreased activity by $38 \%$ as compared to respective controls (13). Metheson et al. also demonstrated a similar observation in rats fed a $2 \%$ cholestyramine diet (14). 


\section{MATERIALS AND METHODS}

Animals and diets. Male Wistar rats, weighing $100 \mathrm{~g}$, were obtained from Japan SLC (Hamamatsu, Japan). The rats were housed in individual cages with screen bottoms of stainless steel in a room maintained at $23 \pm 1^{\circ} \mathrm{C}$ with lighting from 0700 to 1900 . Rats were acclimated by feeding a $20 \%$ casein, cholesterol-free diet for $8 \mathrm{~d}$. Taurine was supplied from Taisho Pharmaceutical Co., Ltd. (Tokyo, Japan).

The study was approved by the University of Shizuoka Animal Use Committee, and the animals were maintained in accordance with the guidelines for the care and use of laboratory animals, University of Shizuoka.

After acclimation, the rats were divided into four groups of six each based on body weight and plasma cholesterol concentration. The composition of the $C$ diet was as follows $(\mathrm{g} / \mathrm{kg})$ : casein, 200.0; $\alpha$-cornstarch, 427.4; sucrose, 213.6; corn oil, 50; AIN-93G mineral mix (15), 35; AIN-93 vitamin mix (15), 10; choline chloride, 1.5; cellulose, 50.0; cholesterol, 10.0; and sodium cholate, 2.5 . The $\mathrm{CH}$ group was fed a diet prepared by adding $40.0 \mathrm{~g}$ cholestyramine/kg $\mathrm{C}$ diet. The BA group was fed the $\mathrm{C}$ diet supplemented with $7.5 \mathrm{~g} / \mathrm{kg}$ sodium cholate. The taurine groups (CT, CHT and BAT) were fed the diet supplemented with $30.0 \mathrm{~g} / \mathrm{kg}$ for each diet. The rats were fed these diets ad libitum for $14 \mathrm{~d}$. In the present study, four test groups were used in a $2 \times 2$ design of $\mathrm{C}$ or $\mathrm{CT}$ and $\mathrm{CH}$ or $\mathrm{CHT}$ for Experiment 1, and $\mathrm{C}$ or $\mathrm{CT}$ and $\mathrm{BA}$ or BAT in Experiment 2. Blood samples $(50 \mu \mathrm{L})$ were collected into a glass hematocrit tube containing heparin from the tail veins at $1000-1100 \mathrm{~h}$ on days 0,7 and 14 to determine the total plasma cholesterol concentration.

At the end of the experimental period, the rats were anesthetized by intraperitoneal injection of sodium pentobarbital ( $50 \mathrm{mg} / \mathrm{kg}$ body wt.), and sacrificed between 2300 and 0100 to examine the effects of taurine on the activity of CYP7A1. Blood was drawn through an abdominal aorta puncture into a centrifugation tube via a catheter, and serum was separated by centrifugation at $1,200 \times g$ for $20 \mathrm{~min}$ at $4^{\circ} \mathrm{C}$. The liver was immediately removed after perfusion with ice-cold $100 \mathrm{mmol} / \mathrm{L}$ potassium phosphate buffer (containing $1 \mathrm{mmol} / \mathrm{L}$ of

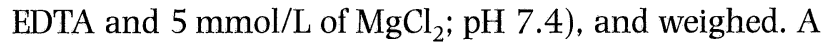
$2 \mathrm{~g}$ liver portion was quickly homogenized in $7 \mathrm{~mL}$ of ice-cold $100 \mathrm{mmol} / \mathrm{L}$ potassium phosphate buffer containing $1 \mathrm{mmol} / \mathrm{L}$ of EDTA and $5 \mathrm{mmol} / \mathrm{L}$ of $\mathrm{MgCl}_{2}(\mathrm{pH}$ 7.4) using a loose-fitting Teflon pestle. The homogenate was centrifuged at $9,000 \times g\left(30 \mathrm{~min}, 4^{\circ} \mathrm{C}\right)$; the supernatant thus obtained was then centrifuged at $100,000 \times g\left(60 \mathrm{~min}, 4^{\circ} \mathrm{C}\right)$. The pellets were resuspended in $3.5 \mathrm{~mL}$ of the buffer and centrifuged again. The resulting pellets were homogenized in $2.4 \mathrm{~mL}$ of the buffer. The microsomal preparation was immediately frozen in liquid nitrogen and stored at $-80^{\circ} \mathrm{C}$ until measurement of CYP7A1 activity. The protein content of the preparation was determined using a commercial kit (DC Protein Assay, Bio-Rad, Yokohama, Japan).
Another portion of the liver was immediately frozen in liquid nitrogen and stored at $-80^{\circ} \mathrm{C}$ until the analysis of cholesterol, bile acid, and taurine was conducted. For the determination of total bile acids excreted into feces, the feces were collected during the last $3 \mathrm{~d}$ of the experimental period, lyophilized, weighed, and stored at $-40^{\circ} \mathrm{C}$.

Biochemical analyses. Plasma cholesterol concentration was determined by an enzymatic method using a commercial kit (Cholesterol C-test, Wako Pure Chemical Industries, Ltd., Osaka, Japan). The plasma (VLDL+LDL) fraction was precipitated with a heparin:manganese reagent (Wako), and the supernatant (the HDL fraction) was assayed for HDL-cholesterol using a commercial kit (HDL-cholesterol test, Wako). The concentration of (VLDL+LDL) cholesterol was calculated as the difference between total plasma cholesterol concentration and HDL cholesterol concentration. Plasma triglyceride and phospholipid concentrations were measured using a commercial kit (Triglyceride G test and Phospholipid B test, respectively, Wako). Serum and liver taurine concentrations were determined with an amino acid analyzer (ALC-1000, Shimadzu, Kyoto, Japan) after deproteinization by $100 \mathrm{~g} / \mathrm{L}$ of a trichloroacetic acid solution. Liver cholesterol was analyzed using a commercial kit (Cholesterol C test) following the method of Morita et al. (16) after the extraction of lipids from the liver by the method of Folch et al. (17) The activity of hepatic CYP7A1 was measured in microsomal fractions as described by Ogishima and Okuda (18), with a slight modification. In brief, the microsome was incubated at $37^{\circ} \mathrm{C}$ for $25 \mathrm{~min}$ in $100 \mathrm{mmol} / \mathrm{L}$ of potassium phosphate buffer $(\mathrm{pH}$ 7.4) containing $1 \mathrm{mmol} / \mathrm{L}$ of EDTA, $5 \mathrm{mmol} / \mathrm{L}$ of $\mathrm{MgCl}_{2}, 20 \mathrm{mmol} / \mathrm{L}$ of cysteamine, $1 \mathrm{mmol} / \mathrm{L}$ of NADP, $10 \mathrm{mmol} / \mathrm{L}$ of glucose6-phosphate, and 2.5 units/mL of glucose-6-phosphate dehydrogenase. After termination of the reaction with $60 \mathrm{~g} / \mathrm{L}$ of sodium cholate, a cholesterol oxydase solution (Type A, TOYOBO, Tokyo, Japan) was added to the reaction solution for the conversion of $7 \alpha$-hydroxycholesterol into $7 \alpha$-hydroxy-4-cholesten-3-one, and then the solution was incubated at $37^{\circ} \mathrm{C}$ for another $30 \mathrm{~min}$. After the reaction was stopped by adding methanol, the extraction of $7 \alpha$-hydroxy-4-cholesten-3-one by petroleum ether was carried out. The content of $7 \alpha$-hydroxy4-cholesten-3-one was determined by HPLC equipped with a Waters Spherisorb (5 $\mu \mathrm{m}$ Silica, $4.6 \times 250 \mathrm{~mm}$, Waters, Tokyo, Japan) column at a wavelength of $240 \mathrm{~nm}$. The activity of hepatic CYP7A1 was expressed as $\mathrm{pmol} /(\mathrm{min} \cdot \mathrm{mg}$ protein). Total fecal bile acids were extracted from lyophilized feces with a mixture of chloroform-methanol $(1: 1, \mathrm{v} / \mathrm{v})$ at $70^{\circ} \mathrm{C}$ for $60 \mathrm{~h}(19)$ and analyzed enzymatically by a slightly modified Sheltaway and Lowosky $3 \alpha$-hydroxysteroid dehydrogenase assay (20). Lithocholic acid was used as the standard substrate.

Statistical analysis. Experimental data were statistically analyzed by two-way ANOVA (21). When the interactions (cholestyramine $\times$ taurine in experiment 1 and content of bile acid $\times$ taurine in experiment 2 ) were 
significant $(p<0.05)$, Fisher's least significant difference test was performed (21).

\section{RESULTS}

\section{Experiment 1}

Body weight gain did not differ among all groups $(88 \pm 2,85 \pm 3,88 \pm 2$, and $80 \pm 4 \mathrm{~g} / 14 \mathrm{~d}$ for rats fed the $\mathrm{C}, \mathrm{CT}, \mathrm{CH}$, and CHT diets, respectively). Food intake was significantly greater in rats fed the $\mathrm{CH}$ and CHT diets $(276 \pm 4$ and $260 \pm 10 \mathrm{~g} / 14 \mathrm{~d})$ than in those fed the $\mathrm{C}$ and $\mathrm{CT}$ diets $(249 \pm 4$ and $253 \pm 8 \mathrm{~g} / 14 \mathrm{~d}$, ANOVA analysis, $p=0.026$ ). Figure 1 shows the time-course of plasma cholesterol concentrations. The plasma cholesterol concentration in rats fed the $\mathrm{C}$ diet rose remarkably over time, but the rise was suppressed in rats fed the CT diet. The elevation of plasma cholesterol concentration was suppressed in rats fed the $\mathrm{CH}$ diet, and taurine intake did not significantly reduce plasma cholesterol. Table 1 shows the lipid concentration in the serum and liver, hepatic CYP7A1 activity, and the content of fecal bile acids. Serum cholesterol concentrations were significantly lower in rats fed the $\mathrm{CT}, \mathrm{CH}$, and CHT diets than in those fed the $\mathrm{C}$ diet. HDL-cholesterol concentrations in the serum were higher in taurine-fed rats than in rats fed the taurine-free diet, and a significant elevation of HDL-cholesterol concentration was observed in rats fed the $\mathrm{CH}$ and $\mathrm{CHT}$ diets. Liver cholesterol concentrations were significantly lowered by the administration of either taurine or cholestyramine. Furthermore, there was no significant interaction between taurine and cholestyramine in the liver cholesterol concentration. There was a tendency for CYP7A1 activity to increase in the hepatic microsome due to the feeding of taurine in the absence of cholestyramine (CT group). Hepatic CYP7A1 activity was significantly lower in rats fed cholestyramine (CH and CHT groups) than in those fed cholestyramine-free diets (C and CT groups). Bile acid excretion into the feces greatly increased in the $\mathrm{CT}, \mathrm{CH}$, and CHT groups that showed

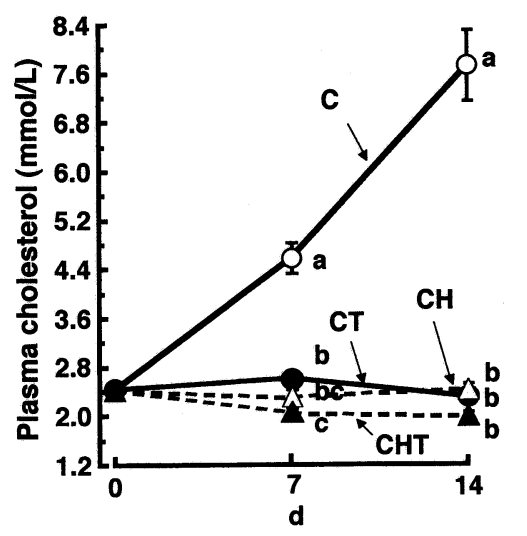

Fig. 1. Changes in plasma cholesterol concentration in rats fed taurine-free or taurine diets supplemented with or without $4 \%$ cholestyramine (Experiment 1 ). Each point is the mean from six rats, and the vertical bars represent SE. Values not sharing a common letter are significantly different $(p<0.05)$. Statistical comparisons were made with Fisher's least significant difference test. C, control diet containing $10 \mathrm{~g}$ cholesterol $/ \mathrm{kg}$ and $2.5 \mathrm{~g}$ sodium cholate/kg; CT, $\mathrm{C}$ diet containing $30 \mathrm{~g}$ taurine $/ \mathrm{kg} ; \mathrm{CH}, \mathrm{C}$ diet containing $4 \%$ cholestyramine; $\mathrm{CHT}, \mathrm{CH}$ diet containing 3\% taurine. Lines show the cholestyramine-free groups ( $\mathrm{C}$ and $\mathrm{CT}$ ), and broken lines indicate the cholestyramine-fed groups ( $\mathrm{CH}$ and $\mathrm{CHT})$.

Table 1. Effect of taurine on serum taurine and cholesterol, liver taurine, steroids and cholesterol $7 \alpha$-hydroxylase activity, and fecal bile acid excretion in rats fed high-cholesterol diets supplemented with or without $4 \%$ cholestyramine. $^{1}$

\begin{tabular}{|c|c|c|c|c|c|c|c|}
\hline & \multicolumn{4}{|c|}{ Groups $^{2}$} & \multicolumn{3}{|c|}{ Two-way ANOVA ${ }^{2}$} \\
\hline & $\mathrm{C}$ & $\mathrm{CT}$ & $\mathrm{CH}$ & $\mathrm{CHT}$ & $\mathrm{CH}$ & Taurine & $\begin{array}{c}\mathrm{CH} \times \\
\text { taurine }\end{array}$ \\
\hline Serum taurine, $\mu \mathrm{mol} / \mathrm{L}$ & $164.5 \pm 4.8$ & $935.9 \pm 14.2$ & $148.1 \pm 9.7$ & $931.2 \pm 7.7$ & 0.290 & $<0.001$ & 0.555 \\
\hline \multicolumn{8}{|l|}{ Serum cholesterol, $\mathrm{mmol} / \mathrm{L}$} \\
\hline Total & $4.75 \pm 0.41^{\mathrm{a}}$ & $2.05 \pm 0.17^{\mathrm{b}}$ & $2.26 \pm 0.11^{b}$ & $1.96 \pm 0.09^{b}$ & $<0.001$ & $<0.001$ & $<0.001$ \\
\hline HDL & $0.638 \pm 0.033^{c}$ & $0.836 \pm 0.041^{b}$ & $1.35 \pm 0.08^{\mathrm{a}}$ & $1.27 \pm 0.07^{\mathrm{a}}$ & $<0.001$ & 0.319 & 0.038 \\
\hline Serum triglycerides, g/L & $1.07 \pm 0.06$ & $0.967 \pm 0.075$ & $1.03 \pm 0.13$ & $0.866 \pm 0.040$ & 0.402 & 0.131 & 0.715 \\
\hline Serum phospholipids, g/L & $1.85 \pm 0.06$ & $1.56 \pm 0.06$ & $1.99 \pm 0.07$ & $1.79 \pm 0.05$ & 0.006 & $<0.001$ & 0.515 \\
\hline \multicolumn{8}{|l|}{ Liver } \\
\hline Weight, g/100 g body wt. & $5.80 \pm 0.15$ & $5.74 \pm 0.12$ & $4.51 \pm 0.11$ & $4.35 \pm 0.10$ & $<0.001$ & 0.393 & 0.666 \\
\hline Taurine, $\mu \mathrm{mol} / \mathrm{g}$ liver & $0.347 \pm 0.023$ & $4.57 \pm 0.03$ & $1.07 \pm 0.35$ & $4.56 \pm 0.05$ & 0.074 & $<0.001$ & 0.064 \\
\hline Cholesterol, $\mu \mathrm{mol} / \mathrm{g}$ liver & $36.9 \pm 2.1$ & $30.6 \pm 0.8$ & $19.1 \pm 1.6$ & $11.5 \pm 0.9$ & $<0.001$ & $<0.001$ & 0.680 \\
\hline $\begin{array}{l}\mathrm{CYP} 7 \mathrm{~A} 1,{ }^{2} \mathrm{pmol} / \mathrm{min} / \mathrm{mg} \\
\text { protein }\end{array}$ & $27.4 \pm 3.9$ & $40.6 \pm 7.6$ & $19.8 \pm 3.1$ & $20.1 \pm 1.4$ & 0.006 & 0.157 & 0.176 \\
\hline \multicolumn{8}{|l|}{ Feces } \\
\hline Weight, g/d & $2.07 \pm 0.06^{\mathrm{c}}$ & $2.15 \pm 0.09^{c}$ & $3.96 \pm 0.11^{\mathrm{a}}$ & $3.47 \pm 0.12^{b}$ & $<0.001$ & 0.048 & 0.008 \\
\hline Bile acids, $\mu \mathrm{mol} / \mathrm{d}$ & $135.0 \pm 4.9$ & $180.0 \pm 2.7$ & $169.2 \pm 7.9$ & $189.1 \pm 16.0$ & 0.032 & 0.003 & 0.194 \\
\hline
\end{tabular}

\footnotetext{
${ }^{1}$ Values are means \pm SE $(n=6)$. Values in a row not sharing a common superscript letter are significantly different when tested by two-way ANOVA and Fisher's least significant difference test, $p<0.05$.

${ }^{2} \mathrm{C}$, control diet containing $1 \%$ cholesterol and $0.25 \%$ sodium cholate; $\mathrm{CT}$, $\mathrm{C}$ diet containing $3 \%$ taurine; $\mathrm{CH}$, $\mathrm{C}$ diet containing $4 \%$ cholestyramine; CHT, CH diet containing 3\% taurine; CYP7A1, cholesterol $7 \alpha$-hydroxylase.
} 
lower serum cholesterol concentrations.

Experiment 2

Body weight gains were significantly lower in rats fed the BA and BAT diets $(73 \pm 2$ and $74 \pm 2 \mathrm{~g} / 14 \mathrm{~d})$ than in those fed the $\mathrm{C}$ and $\mathrm{CT}$ diets $(88 \pm 2$ and $85 \pm 3 \mathrm{~g} / 14 \mathrm{~d}$, ANOVA analysis, $p<0.001)$. Food intake did not differ among the groups $(249 \pm 4,253 \pm 8,241 \pm 3$, and $246 \pm 3 \mathrm{~g} / 14 \mathrm{~d}$ for rats fed the C, CT, BA, and BAT diets, respectively). Figure 2 shows the time course of plasma cholesterol. The plasma cholesterol concentration in rats fed the $\mathrm{C}$ diet rose remarkably over time. Plasma cholesterol concentration was significantly higher in rats fed the BA diet than in those fed the $\mathrm{C}$ diet. Low levels of plasma cholesterol were observed in groups fed the $\mathrm{CT}$ and BAT diets as compared to respective control groups (C and BA groups). Table 2 indicates the lipid concentrations in the serum and liver, hepatic CYP7A1 activity, and the content of fecal bile acid. Serum cholesterol concentrations were significantly higher in rats fed the $\mathrm{C}$ diet than in those fed the CT diet. The extent of the increase in serum cholesterol concentrations in rats fed the BA diet was greater than in those fed the $\mathrm{C}$ diet. Serum HDL-cholesterol concentration was significantly decreased by the administration of high bile acid, while it was increased by taurine feeding. Significant reductions in liver cholesterol by taurine feeding were observed. Liver cholesterol was significantly elevated by the ingestion of a large amount of bile acid. Hepatic CYP7A1 activity was significantly elevated by taurine intake and increased 2-fold when the diet was supplemented with a high bile acid content. Hepatic CYP7A1 activity was not affected by the intake of large amounts of bile acid (BA and BAT groups). Fecal bile acid excre- tion was significantly increased by the ingestion of high bile acid. Taurine feeding caused increased bile acid excretion into the feces in the CT group, but not in the BAT group.

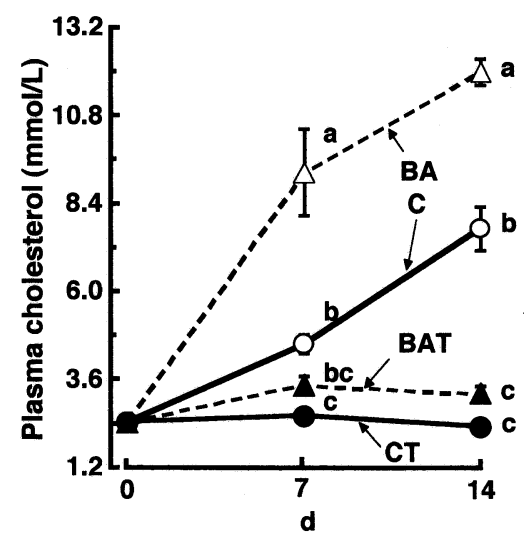

Fig. 2. Changes in plasma cholesterol concentration in rats fed taurine-free or taurine diets supplemented with low and high contents of sodium cholate (Experiment 2). Each point is the mean from six rats, and the vertical bars represent SE. Values not sharing a common letter are significantly different $(p<0.05)$. Statistical comparisons were made with Fisher's least significant difference test. $\mathrm{C}$, control diet containing $10 \mathrm{~g}$ cholesterol $/ \mathrm{kg}$ and $2.5 \mathrm{~g}$ sodium cholate $/ \mathrm{kg}$; CT, $\mathrm{HC}$ diet containing $30 \mathrm{~g}$ taurine $/ \mathrm{kg}$; BA, C diet containing $7.5 \mathrm{~g}$ sodium cholate/kg; BAT, BA diet containing $30 \mathrm{~g}$ taurine $/ \mathrm{kg}$. Lines show the low bile acid groups ( $\mathrm{C}$ and $\mathrm{CT})$, and broken lines indicate the high bile acid groups (BA and BAT).

Table 2. Effect of taurine on serum taurine and cholesterol, liver taurine, steroids and cholesterol $7 \alpha$-hydroxylase activity, and fecal bile acid excretion in rats fed high-cholesterol diets supplemented with $0.25 \%$ or $1 \%$ sodium cholate. ${ }^{1}$

\begin{tabular}{|c|c|c|c|c|c|c|c|}
\hline & \multicolumn{4}{|c|}{ Groups $^{2}$} & \multicolumn{3}{|c|}{ Two-way ANOVA } \\
\hline & $\mathrm{C}$ & $\mathrm{CT}$ & BA & BAT & Bile acid & Taurine & $\begin{array}{l}\text { Bile acid } \\
\times \text { taurine }\end{array}$ \\
\hline Serum taurine, $\mu \mathrm{mol} / \mathrm{L}$ & $164.5 \pm 4.8$ & $935.9 \pm 14.2$ & $144.1 \pm 6.4$ & $941.8 \pm 2.0$ & 0.387 & $<0.001$ & 0.126 \\
\hline \multicolumn{8}{|l|}{ Serum cholesterol, $\mathrm{mmol} / \mathrm{L}$} \\
\hline Total & $4.75 \pm 0.41^{b}$ & $2.05 \pm 0.17^{\mathrm{c}}$ & $7.80 \pm 0.17^{\mathrm{a}}$ & $2.23 \pm 0.17^{\mathrm{c}}$ & $<0.001$ & $<0.001$ & $<0.001$ \\
\hline HDL & $0.638 \pm 0.033$ & $0.836 \pm 0.041$ & $0.469 \pm 0.024$ & $0.624 \pm 0.030$ & $<0.001$ & $<0.001$ & 0.516 \\
\hline Serum triglycerides, $\mathrm{g} / \mathrm{L}$ & $1.07 \pm 0.06$ & $0.967 \pm 0.08$ & $0.988 \pm 0.05$ & $1.02 \pm 0.08$ & 0.864 & 0.630 & 0.319 \\
\hline Serum phospholipids, g/L & $1.85 \pm 0.06^{\mathrm{a}}$ & $1.58 \pm 0.06^{\mathrm{b}}$ & $1.98 \pm 0.04^{\mathrm{a}}$ & $1.43 \pm 0.06^{\mathrm{b}}$ & 0.966 & $<0.001$ & 0.018 \\
\hline \multicolumn{8}{|l|}{ Liver } \\
\hline Weight, g/100 g body wt. & $5.80 \pm 0.15$ & $5.74 \pm 0.12$ & $6.11 \pm 0.13$ & $5.74 \pm 0.19$ & 0.304 & 0.178 & 0.307 \\
\hline Taurine, $\mu \mathrm{mol} / \mathrm{g}$ liver & $0.347 \pm 0.023$ & $4.57 \pm 0.03$ & $0.402 \pm 0.019$ & $4.51 \pm 0.06$ & 0.943 & $<0.001$ & 0.136 \\
\hline Cholesterol, $\mu \mathrm{mol} / \mathrm{g}$ liver & $36.9 \pm 2.1^{\mathrm{b}}$ & $30.6 \pm 0.8^{c}$ & $46.9 \pm 2.1^{\mathrm{a}}$ & $32.0 \pm 1.5^{\mathrm{bc}}$ & 0.005 & $<0.001$ & 0.027 \\
\hline $\begin{array}{l}\mathrm{CYP} 7 \mathrm{~A} 1,{ }^{2} \mathrm{pmol} / \mathrm{min} / \mathrm{mg} \\
\text { protein }\end{array}$ & $27.4 \pm 3.9$ & $40.6 \pm 7.6$ & $25.7 \pm 2.9$ & $49.0 \pm 2.8$ & 0.487 & $<0.001$ & 0.293 \\
\hline \multicolumn{8}{|l|}{ Feces } \\
\hline Weight, g/d & $2.07 \pm 0.06$ & $2.15 \pm 0.09$ & $2.51 \pm 0.04$ & $2.27 \pm 0.13$ & 0.003 & 0.352 & 0.072 \\
\hline Bile acids, $\mu \mathrm{mol} / \mathrm{d}$ & $135.0 \pm 4.9^{c}$ & $180.0 \pm 2.7^{b}$ & $333.7 \pm 4.5^{\mathrm{a}}$ & $331.5 \pm 17.9^{\mathrm{a}}$ & $<0.001$ & 0.038 & 0.024 \\
\hline
\end{tabular}

${ }^{1}$ Values are means \pm SE $(n=6)$. Values in a row not sharing a common superscript letter are significantly different when tested by two-way ANOVA and Fisher's least significant difference test, $p<0.05$.

${ }^{2} \mathrm{C}$, control diet containing $1 \%$ cholesterol and $0.25 \%$ sodium cholate; CT, HC diet containing 3\% taurine; BA, C diet containing $0.75 \%$ sodium cholate; BAT, BA diet containing 3\% taurine; CYP7A1, cholesterol $7 \alpha$-hydroxylase. 


\section{DISCUSSION}

We found that, in rats fed diets supplemented with $1 \%$ cholesterol and $0.25 \%$ sodium cholate, the hypocholesterolemic effect of taurine is associated with the degradation of cholesterol, which is associated with cholesterol $7 \alpha$-hydroxylase (CYP7A1) (7). In rats fed a high cholesterol diet, cholesterol balance is dependent on the catabolism of cholesterol because cholesterol synthesis is abolished in these rats. Therefore, the degradation pathway of cholesterol in the liver would be at least one of the main mechanisms for the reduction of serum cholesterol levels by taurine feeding. However, it is unclear how taurine is involved in the induction of CYP7A1 gene expression and its activity. Synthesis of bile acids from cholesterol is regulated by the feedback inhibition of CYP7A1 in the form of bile acids returning to the liver via enterohepatic circulation (22). Additionally, the bile acid pool is maintained by efficient enterohepatic circulation. Therefore, changes in the bile acid pool size are the result of changes in fecal bile acid excretion and/or hepatic bile acid synthesis. In the present and previous studies, bile acid excretion into the feces was elevated by taurine feeding (7). Therefore, taurine feeding may be involved in the alternation of the bile acid pool size, which would partially contribute to the facilitation of hepatic CYP7A1 gene expression and its activity.

We used a large amount of bile acid and cholestyramine for changing the bile acid pool size. Cholestyramine and large amounts of bile acid alter the intestinal pool size of bile acids due to the inhibition of bile acid absorption from the ileum and an increase in exogenous bile acid, respectively $(23,24)$. Cholestyramine also promotes hepatic CYP7A1 activity, resulting in decreased serum cholesterol concentration (25). Taurine reduced the serum cholesterol concentration in rats fed a large amount of bile acid but not in those fed cholestyramine. Therefore, the serum cholesterol-lowering effect of taurine may be related to the increased pool size of bile acid due to the inhibition of bile acid absorption or the up-regulation of CYP7A1 activity. However, the effect of taurine on hepatic CYP7A1 activity and serum cholesterol concentration would still occur despite the variation of bile acid pool size due to an increase in exogenous bile acid.

It is well known that cholestyramine feeding increases hepatic CYP7A1 activity, while high bile acid feeding inhibits this enzyme activity $(13,14,26,27)$. In the present study, hepatic CYP7A1 activity was reduced by cholestyramine feeding, whereas this is not in agreement with previous investigations $(13,14,26,27)$. Horton et al. reported that hepatic CYP7A1 activity and its mRNA were elevated 2.5-fold and 2.8-fold in rats fed a $1 \%$ cholestyramine diet supplemented without both cholesterol and bile acid (28). Furthermore, Pandak et al. reported that hepatic activity rose $200 \%$ in rats fed a 5\% cholestyramine diet supplemented without cholesterol (13). Thus, cholestyramine seems to up-regulate hepatic CYP7A1 activity when rats are fed a cholesterol-free diet. The different responses of cholestyramine feeding on CYP7A1 activity might result from the different content of cholesterol and sodium cholate added to diets. However, there has been no investigation of cholestyramine in animals fed diets supplemented with both cholesterol and bile sodium cholate. Moreover, in the present study, hepatic CYP7A1 activity was not affected by the administration of a large amount of bile acid. However, this result is also opposite of previous studies $(13,14,26)$. Pandak et al. reported that a $1 \%$ sodium cholate diet supplemented without cholesterol decreased hepatic CYP7A1 activity by $38 \%$ as compared to controls (13). Therefore, the negative feedback regulation of CYP7A1 by bile acid may occur only in rats fed a cholesterol-free diet. Therefore, it is presumed that, in the present study, the different response of high bile acid feeding on CYP7A1 activity resulted from the coexistence of a positive factor (cholesterol) and a negative factor (sodium cholate) in the diets.

In the present study, the diet conditions were consequently complex. However, it is apparent that CYP7A1 is induced by taurine intake, which then reduces serum cholesterol. Therefore, it appears that the degradation of cholesterol into bile acids plays an important role in the effect of taurine. In summary, it is suggested that taurine induces the catabolism of cholesterol to bile acids through hepatic CYP7A1 activity, even though the bile acid pool size is increased by the administration of exogenous bile acid, resulting in the reduction of serum cholesterol. Moreover, the mechanism of hypocholesterolemic effect due to taurine may be similar to that due to cholestyramine.

\section{Acknowledgments}

This study was supported by a grant from Taisho Pharmaceutical Co., Ltd., Tokyo, Japan.

\section{REFERENCES}

1) Kannel WB, Castelli WP, Gordon T, McNamara PM. 1971. Serum cholesterol, lipoproteins, and the risk of coronary heart disease. The Framington study. Ann Intern Med 74: 1-12.

2) Stamler J. 1965. Role of cholesterol in atherosclerosis. Acta Cardiol Suppl 11: 499.

3) Tsuji K, Seki T, Iwao H. 1979. Cholesterol-lowering effects of taurine and sulfur-containing amino acids in serum and liver of rats. Sulfur-Containing Amino Acids 2: 143-145.

4) Masuda M, Horisaka K. 1986. Effect of taurine and homotaurine on bile acid metabolism in dietary hyperlipidemic rats. J Pharmacobiodyn 9: 934-940.

5) Murakami S, Kondo-Ohta Y, Tomisawa K. 1999. Improvement in cholesterol metabolism in mice given chronic treatment of taurine and fed a high-fat diet. Life Sci 64: 83-91.

6) Park T, Lee K. 1998. Dietary taurine supplementation reduces plasma and liver cholesterol and triglyceride levels in rats fed a high-cholesterol or a cholesterol-free diet. Adv Exp Med Biol 442: 319-325.

7) Yokogoshi H, Mochizuki H, Nanami K, Hida Y, Miyachi F, Oda H. 1999. Dietary taurine enhances cholesterol 
degradation and reduces serum and liver cholesterol concentrations in rats fed a high-cholesterol diet. J Nutr 129: 1705-1712.

8) Mochizuki H, Takido J, Oda H, Yokogoshi H. 1999. Improving effect of dietary taurine on marked hypercholesterolemia induced by a high-cholesterol diet in streptozotocin-induced diabetic rats. Biosci Biotechnol Biochem 63: 1984-1987.

9) Mochizuki H, Takido J, Yokogoshi H. 1999. Improved suppression by dietary taurine of the fecal excretion of bile acids from hypothyroid rats. Biosci Biotechnol Biochem 63: 753-755.

10) Mochizuki H, Oda H, Yokogoshi H. 2001. Dietary taurine potentiates polychlorinated biphenyl-induced hypercholesterolemia in rats. $J$ Nutr Biochem 12: 109-115.

11) Le Dafniet M, Pessayre D, Le Quernec L, Erlinger S. 1981. Effects of troleandomycin administration on cholesterol $7 \alpha$-hydroxylase activity and bile secretion in rats. J Pharmacol Exp Ther 219: 558-562.

12) Xu G, Salen G, Shefer S, Tint GS, Nguyen LB, Chen TS, Greenblatt D. 1999. Increasing dietary cholesterol induces different regulation of classic and alternative bile acid synthesis. J Clin Invest 103: 89-95.

13) Pandak WM, Vlahcevic ZR, Heuman DM, Redford KS, Chiang JY, Hylemon PB. 1994. Effects of different bile salts on steady-state mRNA levels and transcriptional activity of cholesterol $7 \alpha$-hydroxylase. Hepatology 19: 941-947.

14) Matheson HB, Colon IS, Story JA. 1995. Cholesterol $7 \alpha$-hydroxylase activity is increased by dietary modification with psyllium hydrocolloid, pectin, cholesterol and cholestyramine in rats. J Nutr 125: 454-458.

15) Reeves PG, Nielsen FH, Fahey GC Jr. 1993. AIN-93 purified diets for laboratory rodents: final report of the American Institute of Nutrition ad hoc writing committee on the reformulation of the AIN-76A rodent diet. $J$ Nutr 123: 1939-1951.

16) Morita T, Oh-hashi A, Takei K, Ikai M, Kasaoka S, Kiriyama S. 1997. Cholesterol-lowering effects of soybean, potato and rice proteins depend on their low methionine contents in rats fed a cholesterol-free purified diet. J Nutr 127: 470-477.

17) Folch J, Lees M, Sloane-Stanley GH. 1957. A simple method for the isolation and purification of total lipids from animal tissues. J Biol Chem 226: 497-509.

18) Ogishima T, Okuda K. 1986. An improved method for assay cholesterol $7 \alpha$-hydroxylase activity. Anal Biochem 158: $228-232$.

19) Eneroth P, Hellstrom K, Sjovall J. 1968. A method for quantitative determination of bile acids in human feces. Bile acids and steroids 195. Acta Chem Scand 22: 1729-1744.

20) Sheltaway MJ, Lowosky MS. 1975. Determination of fecal bile acids by an enzymatic method. Clin Chim Acta 64: $127-132$.

21) Snedecor GW, Cochran WG. 1967. Statistical Methods, 6th ed. Iowa State University Press, Ames, IA.

22) Heuman DM, Vlahcevic ZR, Bailey ML, Hylemon PB. 1988. Regulation of bile acid synthesis. II. Effect of bile acid feeding on enzymes regulating hepatic cholesterol and bile acid synthesis in the rat. Hepatology $\mathbf{8}$ : 892-897.

23) Trautwein EA, Kunath-Rau A, Erbersdobler HF. 1999. Increased fecal bile acid excretion and changes in the circulating bile acid pool are involved in the hypocholesterolemic and gallstone-preventive actions of psyllium in hamsters. J Nutr 129: 896-902.

24) Carrella M, Dietschy JM. 1977. Comparison of the effects of cholic acid and chenic acid feeding on rates of cholesterol synthesis in the liver of the rat. Am J Dig Dis 22: 318-326.

25) Buhman KK, Furumoto EJ, Donkin SS, Story JA. 1998. Dietary psyllium increases fecal bile acid excretion, total steroid excretion and bile acid biosynthesis in rats. J Nutr 128: 1199-1203.

26) Jolley CD, Dietschy JM, Turley SD. 2000. Induction of bile acid synthesis by cholesterol and cholestyramine feeding is unimpaired in mice deficient in apolipoprotein AI. Hepatology 32: 1309-1316.

27) Shefer S, Kren BT, Salen G, Steer CJ, Nguyen LB, Chen T, Tint GS, Batta AK. 1995. Regulation of bile acid synthesis by deoxycholic acid in the rat: different effects on cholesterol $7 \alpha$-hydroxylase and sterol 27 -hydroxylase. Hepatology 22: 1215-1221.

28) Horton JD, Cuthbert JA, Spady DK. 1995. Regulation of hepatic $7 \alpha$-hydroxylase expression and response to dietary cholesterol in the rat and hamster. $J$ Biol Chem 270: 5381-5387. 